\title{
Ensino e Educação Especial: análise bibliométrica e metassíntese qualitativa da produção científica indexada na base Web of Science
}

Teaching and Special Education: bibliometric analysis and qualitative meta-

synthesis of the scientific production indexed in the Web of Science database

Enseñanza y Educación Especial: análisis bibliométrico y meta-síntesis cualitativa de la producción científica indexada en la base de datos Web of Science

Mônica Luciana da Silva Pereira

Mestranda e professora no Instituto Federal de Brasília, Brasília, Distrito Federal, Brasil.

monica.pereira@ifb.edu.br

ORCID - https://orcid.org/0000-0002-1208-3451

Mayara Lustosa de Oliveira Barbosa

Doutora pela Universidade Estadual de Campinas, Campinas, São Paulo, Brasil.

mayara.barbosa@ifb.edu.br

ORCID - https://orcid.org/0000-0003-3356-0998

Recebido em 14 maio 2020

Aprovado em 19 de setembro de 2020

Publicado em 26 de outubro de 2020

\section{RESUMO}

Estudos sobre Educação Especial e Inclusiva avançaram ao longo das últimas décadas. Porém, no ensino, nem sempre ocorre uma aplicação imediata e eficaz dos achados científicos. Dessa forma, é de extrema importância que haja uma sistematização das publicações, de modo a facilitar a divulgação e incentivar suas aplicações. O objetivo deste estudo foi realizar uma análise bibliométrica da produção científica na área de ensino na Educação Especial e Inclusiva, pela base de dados Web of Science de 1947 a 2020. Os dados levantados foram: número de publicações, autores e periódicos mais proeminentes, países que mais publicaram e principais agências financiadoras. Além disso, por meio da metassíntese, foram analisados artigos relacionados às categorias pesquisa educacional e educação especial. Como resultados, foi possível identificar 10.138 artigos em 1.752 fontes ao longo dos quase 73 anos, sendo a taxa de crescimento anual de 6,3\%. A revista com maior número de publicações no período foi a Exceptional Children, a agência que mais financiou pesquisas foi o Departamento de Saúde dos Estados Unidos - Serviços Humanos. Os países que mais publicaram foram Estados Unidos, seguido pelo Brasil, e o autor com maior número de produções foi Antonis Katsiyannis. Com relação à metassíntese, foram identificados 27 artigos, cujo foco estava no uso de práticas baseadas em evidências. Os resultados encontrados podem ter implicações no sentido de guiar Docentes que atuam com alunos com NEE, pós-graduandos que tenham interesse em especializar-se e 
http://dx.doi.org/10.5902/1984686X44283

Pesquisadores que atuam com a temática e querem estabelecer redes de colaborações mais proeminentes.

Palavras-chave: Educação Especial; práticas de ensino; bibliometria.

\section{ABSTRACT}

Studies on Special and Inclusive Education have advanced over the past decades. However, in teaching, an immediate and effective application of scientific findings does not always happen. Thus, it is extremely important to have a publication systematization, to facilitate the dissemination and encourage their applications. The objective of this study was to carry out a bibliometric analysis of scientific production in the area of Special and Inclusive Education teaching, using the Web of Science database from 1947 to 2020. The data collected were: number of publications, authors and most prominent journals, countries that most published and main funding agencies. In addition, articles related to the categories educational research and special education were analyzed through metasynthesis process. As a result, it was possible to identify 10.138 articles in 1.752 sources over almost 73 years, with an annual growth rate of $6.3 \%$. The journal with the largest number of publications in the period was Exceptional Children, the agency that funded most of the research was the United States Department of Health - Human Services. The countries that published the most were the United States, followed by Brazil, and the author with the largest number of productions was Antonis Katsiyannis. Regarding metasynthesis, 27 articles were identified, focusing on the use of evidence-based practices. The results found may have implications in the sense of guiding Professors who work with students with SEN, graduate students who are interested in specializing and Researchers who work with the theme and want to establish more prominent networks collaborations.

Keywords: Special Education; teaching practice; bibliometrics.

\section{RESUMEN}

Los estudios sobre educación especial e inclusiva han avanzado en las últimas décadas. Sin embargo, en la enseñanza, no siempre hay una aplicación inmediata y efectiva de los hallazgos científicos. Por lo tanto, es extremadamente importante que haya una sistematización de las publicaciones, para facilitar la divulgación y fomentar sus aplicaciones. El objetivo de este estudio fue realizar un análisis bibliométrico de la producción científica en el área de la enseñanza en Educación Especial e Inclusiva, utilizando la base de datos de Web of Science de 1947 a 2020. Los datos recopilados fueron: número de publicaciones, autores y revistas más destacadas, principales países y agencias de financiación. Además, a través de la meta-síntesis, se analizaron artículos relacionados con las categorías de investigación educativa y educación especial. Como resultado, fue posible identificar 10,138 artículos en 1,752 fuentes durante casi 73 años, con una tasa de crecimiento anual de 6.3\%. La revista con el mayor número de publicaciones en el período fue Exceptional Children, la agencia que más financió investigaciones fue el Departamento de Salud de los Estados Unidos - Servicios Humanos. Los países que más publicaron fueron Estados Unidos, seguido de Brasil, y el autor con el mayor número de producciones fue Antonis Katsiyannis. Con respecto a la meta-síntesis, se identificaron 27 artículos, centrados en el uso de prácticas basadas en evidencia. Los resultados encontrados pueden tener implicaciones en el sentido de guiar a los profesores que trabajan con estudiantes con NEE, estudiantes graduados interesados en especializarse e investigadores que trabajan con el tema y quieren establecer redes de colaboración más prominentes.

Palabras clave: Educación Especial; método de enseñanza; bibliometría. 
http://dx.doi.org/10.5902/1984686X44283

\section{Introdução}

Os campos de estudo da Educação Especial (EE) e da Educação Inclusiva (El) experimentaram um crescimento significativo nas últimas décadas (HUANG et al., 2019; HERNÁNDEZ-TORRANO; SOMERTON; HELMER, 2020). Contudo, sabe-se que o aumento exponencial na produção de pesquisas científicas nem sempre representa uma aplicação imediata e eficaz do que foi descoberto. Em especial no que diz respeito à educação, onde a lacuna entre a pesquisa e a prática é ainda mais aparente (LAWLOR, et al., 2019).

Assim, apesar de inúmeras pesquisas apontarem a necessidade da adoção de recursos didáticos e métodos de ensino baseados em pesquisas consolidadas, de modo a facilitar o processo de aprendizagem de estudantes com Necessidades Educacionais Especiais (NEE), a lacuna entre a pesquisa e a aplicação em sala de aula se mantém, sendo frequentemente utilizados métodos educacionais por vezes ineficazes e não práticas validadas pela pesquisa (COOK; SCHIRMER, 2003; SNELL, 2003; BURNS, YSSELDYKE, 2009).

Dessa forma, é de extrema importância que haja uma sistematização das publicações na área, de modo a facilitar a divulgação científica das pesquisas com maior impacto e revelar resultados proeminentes para aplicação por parte dos docentes em suas práticas em sala de aula. Afinal, os professores são elementos chave na construção de escolas com propostas inclusivas (DE-BOER; PIJL; MINNAERT, 2011; PEEBLES; MENDAGLIO, 2014), e estas, por sua vez, são os meios mais eficazes para reduzir o preconceito, combater atitudes discriminatórias e, em última instância, levar à criação de uma sociedade mais receptiva (BOOTH; AINSCOW, 2013).

Em seu artigo intitulado Understanding the development of inclusive education system (2005) o Professor Ainscow, da Universidade de Manchester, especialista em equidade e inclusão, aponta que tentativas de generalizações nos métodos de ensino são muito difíceis, mas que diversas experiências de pesquisadores e professores envolvidos no processo devem ser consideradas, de modo a estruturar uma proposta que seja coerente com o contexto de cada um dos protagonistas envolvidos no processo educativo.

Assim, um método de levantamento que permite a divulgação de propostas com maior impacto em determinadas áreas de pesquisa, e que têm se mostrado uma alternativa consistente com as pesquisas atuais é a condução de análises bibliométricas e 
http://dx.doi.org/10.5902/1984686X44283

cienciométricas (HERNÁNDEZ-TORRANO; SOMERTON; HELMER, 2020; VILELARIBEIRO; BENITE; LIMA-RIBEIRO, 2011).

Hernández-Torrano, Somerton e Helmer (2020) afirmam que pesquisas que sintetizam o conhecimento acumulado sobre a El são extremamente importantes, pois fornecem uma visão geral das tendências e perspectivas do campo de conhecimento, bem como insights valiosos para pesquisadores, educadores e formuladores de políticas.

Assim, o presente estudo intenta contribuir com o atual cenário educacional inclusivo brasileiro realizando uma análise bibliométrica da produção científica na área do ensino na EE e Inclusiva, utilizando a produção disponibilizada na base de dados Web of Science (WoS) nos últimos 70 anos (1947-2020).

Outros pesquisadores já conduziram propostas semelhantes. Vilela, Benite e LimaRibeiro (2011) por meio de uma análise cienciométrica, demonstraram as tendências das publicações científicas na área da EE ao longo de 60 anos. Hernández-Torrano, Somerton e Helmer (2020) desenvolveram uma pesquisa bibliométrica na área da $\mathrm{El}$, por meio da base Scopus, em um período de 25 anos. Alkhateeb, Hadidi e Alkhateeb (2016) revisaram a literatura disponível em países árabes e descobriram que, em geral, a pesquisa é escassa na região, tendo se tornado popular apenas a partir de 2006. Amor et al. (2019), por sua vez, examinaram a produtividade e a distribuição geográfica da pesquisa sobre a $\mathrm{El}$, por meio de uma revisão sistemática da literatura em inglês e espanhol durante um período de 15 anos.

Nosso intuito é, além de ampliar a pesquisa dos autores supracitados em termos temporais, incluir também uma análise qualitativa dos artigos mais citados dos últimos 20 anos. O período de 20 anos foi estabelecido tendo em vista marcos nacionais e internacionais que estimularam pesquisas e investimentos na área. Em âmbito internacional, a reunião do Fórum Mundial da Educação, em abril de 2000, em Dakar, Senegal, marcou o estabelecimento do quadro de referência da iniciativa "Educação para Todos", o qual une propostas da EE em uma perspectiva Inclusiva (UNESCO, 2000). Embora a EE não fosse o alvo único do evento, nele a visão estabelecida pela Declaração de Salamanca foi reafirmada e propôs-se a chamada "Estrutura de Ação de Dakar", a qual exigia comprometimento dos governos no sentido de alcançar uma educação básica de qualidade para todos até 2015 .

No âmbito nacional, entre os anos de 2000 e 2002 três documentos oficiais relevantes foram elaborados e publicados: 1) a Resolução CNE/CEB $n^{\circ}$ 2, a qual institui as diretrizes 
http://dx.doi.org/10.5902/1984686X44283

nacionais para a EE na Educação Básica e aponta que os sistemas de ensino devem matricular todos os alunos (BRASIL, 2001a); 2) o Parecer CNE/CP nำ 9, oqual institui as diretrizes curriculares nacionais para a formação de professores, e estabelece que a educação básica deve ser inclusiva (BRASIL, 2002); e 3) o Parecer CNE/CEB no 17 que possui abrangência para além da Educação Básica, e baseia-se em vários documentos sobre EE (BRASIL, 2001b). Vale destacar que no item 4 do documento é afirmado que a inclusão não consiste apenas na permanência física desses alunos junto aos demais, mas deve mover todos os envolvidos no processo a rever concepções e paradigmas, no sentido de permitir o máximo desenvolvimento do potencial daqueles que possuem NEE.

Assim, além de apresentar a trajetória de crescimento da produção na área nos últimos 70 anos, considerando: 1) as redes de pesquisa colaborativa e redes de cocitação; 2) os principais periódicos, autores e publicações no campo; e, 3) os países e agências financiadoras que mais contribuem para o desenvolvimento das propostas; será também conduzida uma metassíntese qualitativa com os artigos mais citados ao longo dos últimos 20 anos, de modo a identificar e divulgar resultados que demonstraram maior impacto recentemente para o ensino de estudantes com NEE.

\section{Procedimentos Metodológicos}

\section{Caracterização da Pesquisa}

Com relação aos objetivos, a presente pesquisa é descritiva-exploratória (GERHARDT; SILVEIRA, 2009), e utilizará a abordagem bibliométrica para sistematizar a literatura a ser revisada, fazendo uso de metadados extraídos do banco de dados da base WoS. A bibliometria é uma técnica quantitativa e estatística de medição dos índices de produção e disseminação do conhecimento científico em determinada área do conhecimento (HUANG et al., 2019).

Comparada a outros métodos, a bibliometria têm a vantagem de coletar e processar grandes quantidades de informações técnicas, ao mesmo tempo em que oferece resultados objetivos e que podem auxiliar na divulgação científica, na identificação de lacunas, na proposição de inovações e de ações políticas baseadas em evidências técnico-científicas (HUANG et al., 2019; PAYUMO; SUTTON, 2015; RAVIKUMAR; AGRAHARI; SINGH, 2015; HASSAN; HADDAWY, 2015). 
http://dx.doi.org/10.5902/1984686X44283

\section{Levantamento e análise dos dados}

De modo a obter um levantamento abrangente da literatura sobre o ensino na perspectiva da EE e Inclusiva nos últimos anos, foi realizada uma pesquisa na base WoS. A base foi escolhida por possuir uma medida internacionalmente aceita com relação aos métodos de avaliação de periódicos, com base no cumprimento dos padrões editoriais e no alto impacto científico, além de ser a principal fonte de dados usada para obter indicadores bibliográficos, alcançando um status de autoridade na identificação de periódicos de alta qualidade globalmente (RAFOLS et al., 2016; TESTA, 2015; LILLIS; CURRY, 2010).

Além disso, a WoS possui uma amplitude relevante de cobertura, visto que reúne quase 9.000 periódicos internacionais considerados mais relevantes nas áreas de ciências puras, sociais, aplicadas e médicas; a base permite também acesso a trabalhos publicados desde 1945 (RIBEIRO et al., 2007).

Vale destacar que a data de início de nossa busca foi demarcada como 1947 pois a primeira publicação na área indexada na base é datada deste ano. Os descritores selecionados para a busca foram "ensino" e "educação especial" ou "educação inclusiva" no período de 1947 a 2020, tal como segue na fórmula TS= (teaching AND "special education" OR "inclusive education"). A busca foi realizada utilizando a ferramenta de pesquisa avançada, assim a adição do item "TS" antes da fórmula, indica que os descritores podem ser encontrados no título, no resumo ou nas palavras-chave do artigo. Ressalta-se que a busca delimitou apenas artigos, excluindo trabalhos publicados em eventos, e foi realizada na segunda semana de abril de 2020. Dessa maneira, artigos publicados posteriormente a essa data não foram elencados na pesquisa.

Uma limitação comum de algumas pesquisas bibliométricas na área da inclusão de pessoas com NEE é utilizar apenas um dos termos "Educação Especial" ou "Educação Inclusiva" em suas buscas, como pode ser verificado no trabalho de Vilela-Ribeiro, Benite e Lima-Ribeiro, (2011). Em uma pesquisa mais recente, Hernández-Torrano, Somerton e Helmer (2020) utilizaram ambos os termos. Como ambos os descritores podem ser utilizados para pesquisas com o mesmo público-alvo, é extremamente relevante que sejam combinados na busca, de modo a obter maior abrangência. Embora a El possua uma vertente que vai além da Educação voltada para pessoas com NEE, a maior parte das publicações internacionais encontradas na busca pelo termo é relacionada a este público, sendo, portanto, essencial sua adição (HERNÁNDEZ-TORRANO; SOMERTON; HELMER, 2020). 
http://dx.doi.org/10.5902/1984686X44283

\section{Análise quantitativa}

Com relação à abordagem da pesquisa, optou-se pela utilização do método misto, o qual sugere uma integração de métodos qualitativos e quantitativos, de modo a obter uma compreensão mais profunda do objeto de estudo (CASTRO et al., 2010).

Estatística descritiva foi aplicada para apresentação dos resultados quantitativos de todos os artigos e revisões publicados nos quase 73 anos cobertos pela base. Reforça-se que, para obtenção e análise de tais dados, todos os arquivos encontrados (10.138 artigos) foram exportados em grupos de 500 artigos por vez, da base WoS para o software RStudio, onde foi utilizado o pacote Bibliometrix (ARIA; CURCCURULLO, 2017) para levantamento das características pretendidas, a saber: 1) quantos artigos foram publicados por ano e qual a taxa média de crescimento anual; 2) quais os principais periódicos, autores e publicações no campo; 3) quais as redes de pesquisa colaborativa; 4) quais os países e agências financiadoras que mais contribuem para o desenvolvimento das propostas na área; e, 5) quais os artigos mais citados nos últimos 20 anos.

Vale pontuar que para obter os gráficos das publicações por ano de cada um dos autores que mais publicaram no período pesquisado, assim como os gráficos das redes de colaboração e cocitação, foi utilizada a ferramenta Biblioshiny que fornece uma interface web para o Bibliometrix.

\section{Análise qualitativa}

Junto à perspectiva quantitativa, foi aplicada a metassíntese qualitativa para análise dos artigos mais citados dos últimos 20 anos. A técnica é, em geral, empregada em associação com a revisão sistemática de literatura e é definida como a integração e síntese interpretativa dos dados dos artigos que compõem a amostra (MATHEUS, 2009, ALENCAR; ALMOULOUD, 2017). Seu objetivo é tornar os resultados das pesquisas mais acessíveis para serem estudados e relacionados entre si, permitindo compará-los e revelar as convergências, a fim de alcançar uma análise teórica mais sintética, ao mesmo tempo em que é robusta e integrada (VOSGERAU; ROMANOWSKI, 2014; MATHEUS, 2009).

As etapas seguidas para a realização da metassíntese tiveram seu fundamento na proposta do UK Cochrane Centre, iniciativa internacional com origem no Reino Unido, que desde 1922 prepara e dissemina revisões sistemáticas, tornando-se a maior referência da pesquisa baseada em evidências (MATHEUS, 2009). 
http://dx.doi.org/10.5902/1984686X44283

A primeira etapa da metassíntese consiste em identificar as questões que irão nortear a revisão ou os objetivos, os quais foram numerados no tópico anterior. A segunda etapa trata da definição dos critérios de inclusão e exclusão dos trabalhos, selecionando pesquisas que são relevantes aos interesses do levantamento. Neste caso, o critério de inclusão foi determinado pelos descritores adicionados na busca da base. Além disso, em última instância, ao considerar os artigos mais citados dos últimos 20 anos, foram selecionadas apenas duas áreas na base: pesquisas educacionais e educação especial (6.456 artigos), de modo a selecionar produções mais específicas para uma avaliação mais criteriosa quanto às práticas de ensino mais utilizadas. Para tanto, primeiro foram listados os 100 artigos mais citados nas duas áreas, e destes, foram selecionados os mais citados dos últimos 20 anos, totalizando 71 artigos.

A terceira etapa foi a realização da leitura, estudo e fichamento dos artigos mais citados, de forma a tornar os resultados mais acessíveis e organizados. Os trabalhos foram lidos e os dados estruturados na forma de tabelas que elencavam o título, o ano, os autores, 0 periódico, a metodologia, os objetivos, resultados e principais conclusões. A partir de então, uma nova seleção foi conduzida, de modo a excluir trabalhos que não estivessem relacionados com propostas de ensino na EE, restando 27 dos 71 artigos. As etapas descritas anteriormente podem ser verificadas no processo representado na figura 1.

Para atender às etapas 4 (Determinar como os estudos se relacionam justapondo os dados) e 5 (Elaborar afirmações concisas e amplas que correspondam ao conteúdo do conjunto dos resultados) os dados dos artigos foram justapostos a partir das convergências apresentadas no tipo de metodologia empregada (pesquisa de campo/empírica ou revisão de literatura) e nos objetivos propostos. A partir de então, afirmações concisas e amplas, abordando aspectos essenciais dos artigos, foram definidas, apresentando a essência do conjunto de dados. Posteriormente, as conclusões que têm implicações adequadas a contextos mais variados, considerando o foco dos trabalhos na área de ensino e EE, foram destacadas. A sexta etapa consiste justamente na elaboração de uma resposta sintética e robusta equivalente aos estudos pesquisados, partindo das prescrições obtidas a partir de cada um deles. Vale ressaltar que as etapas 3, 4, 5 e 6 foram feitas individualmente, passando por validação cruzada, de modo que fosse possível apresentar dados menos subjetivos e mais acurados com relação às pesquisas avaliadas. 
Figura 1 - Processo de seleção dos textos para a metassíntese qualitativa. Foram selecionados 27 artigos

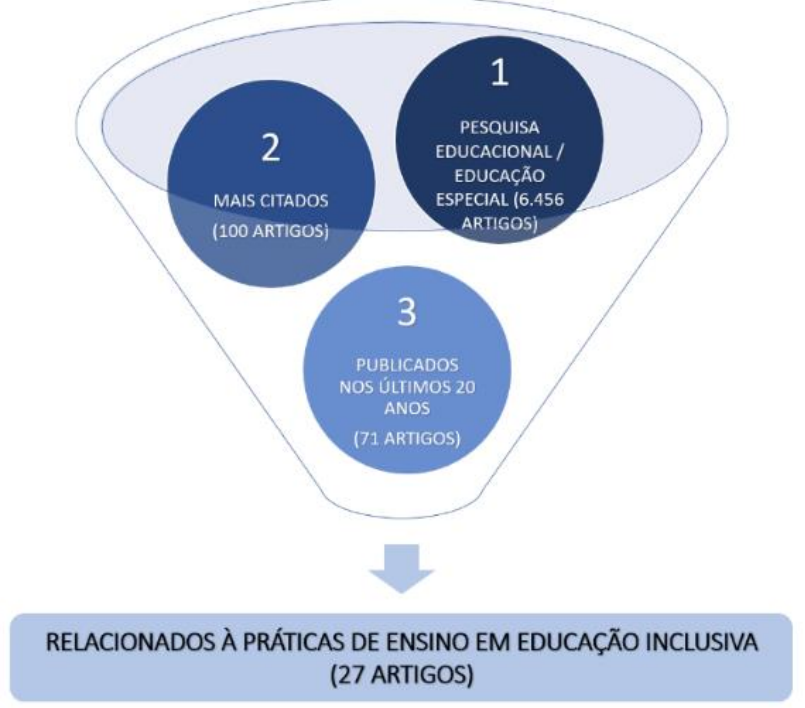

Fonte: elaborada pelas autoras (2020).

\section{Resultados e Discussão}

Crescimento da pesquisa na área, principais periódicos, autores e instituições envolvidas

Foram encontrados 10.138 artigos publicados em 1.752 fontes ao longo dos quase 73 anos considerados na pesquisa. Com relação à quantidade de publicações anuais, é possível verificar no gráfico da Figura 2 que somente no início da década de 90 há um aumento no número de publicações.

Como pontuado por Vilela, Benite e Lima-Ribeiro (2011) a partir dessa década movimentos nacionais e internacionais começaram a se destacar, com a iniciativa de fomentar as políticas de inclusão das pessoas com NEE. Tais movimentos culminaram na realização da Conferência Mundial de EE e na publicação de um documento que representa um marco histórico para a área: a Declaração de Salamanca, em 1994.

Em 2019, ano em que a Declaração de Salamanca completava 25 anos, o número de artigos publicados em um único ano atingiu seu máximo, chegando à 947 publicações, e deixando a taxa de crescimento de publicações anuais na área em $6,3 \%$. Os números podem ser justificados tendo em vista que alguns periódicos realizaram edições especiais ilustrando as maneiras pelas quais a Declaração tem influenciado o desenvolvimento de políticas e práticas em todo o mundo (AINSCOW; SLEE; BEST, 2019). 
http://dx.doi.org/10.5902/1984686X44283

Figura 2 - Número de trabalhos publicados na base WoS de 1947 a 2020

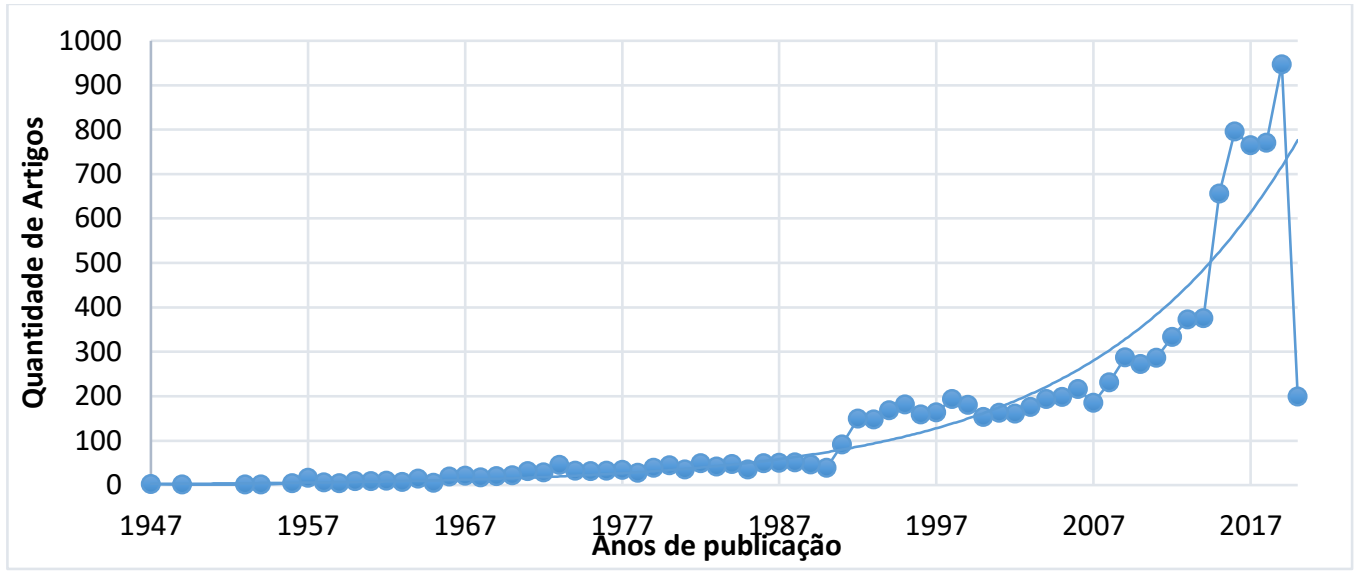

Fonte: Base de Dados WoS (2020).

Com relação aos periódicos com maior número de publicações no período, destacamse os cinco primeiros: 1) Exceptional Children, 2) Remedial and Special Education, 3) Journal of Special Education, 4) International Journal of Inclusive Education, e 5) Journal of Learning Disabilities, todos com mais de 195 artigos publicados no período, como pode ser visto na tabela 1.

Em uma pesquisa bibliométrica recente que considerou o crescimento de várias áreas da educação, incluindo a EE, os autores selecionaram dois dos principais periódicos de cada campo de estudo da educação baseado no impacto do jornal e na opinião de especialistas (HUANG et al., 2019). Nela foram selecionados dois dos 5 periódicos citados acima: Exceptional Children e Journal of Learning Disabilities, demonstrando que as publicações advindas desses periódicos apresentam, de fato, dados relevantes na área do conhecimento.

Lembrando que, pelo fato de a pesquisa buscar por propostas desde o ano de 1947, é possível que periódicos expoentes, como o International Journal of Inclusive Education e o European Journal of Special Needs Education, apareçam em posições mais baixas, por possuírem um aumento no número de pesquisas na área mais recentemente, nos últimos 25 anos (HERNÁNDEZ-TORRANO; SOMERTON; HELMER, 2020). Com vistas a confirmar tal dado, foi gerado o gráfico da Figura 3, o qual revela o crescimento no número de publicações em cada um dos 10 periódicos mais influentes nos últimos anos. 
http://dx.doi.org/10.5902/1984686X44283

Tabela 1 - Fontes mais relevantes para pesquisa na área. Foram selecionados apenas periódicos com mais de 100 artigos publicados na área durante o período estabelecido

\begin{tabular}{ll|c}
\hline \multicolumn{2}{c}{$\begin{array}{c}\text { PERIÓDICOS COM MAIOR NÚMERO DE } \\
\text { PUBLICAÇÕES NA ÁREA }\end{array}$} & $\begin{array}{c}\text { QUANTIDADE DE } \\
\text { ARTIGOS }\end{array}$ \\
\hline 1. Exceptional Children & 499 \\
2. Remedial and Special Education & 421 \\
3. Journal of Special Education & 363 \\
4. International Journal of Inclusive Education & 275 \\
5. Journal of Learning Disabilities & 196 \\
6. Psychology in the Schools & 182 \\
7. Intervention in School and Clinic & 170 \\
8. Behavioral Disorders & 145 \\
9. Topics in Early Childhood Special Education & 132 \\
10. Learning Disability Quarterly & 117 \\
11. Teacher Education and Special Education & 115 \\
12. European Journal of Special Needs Education & 108 \\
\hline
\end{tabular}

Fonte: Base de Dados WoS (2020).

Figura 3 - Crescimento das publicações nos periódicos ao longo dos anos. A revista International Journal of Inclusive Education desponta atualmente como periódico com maior número de publicações na área

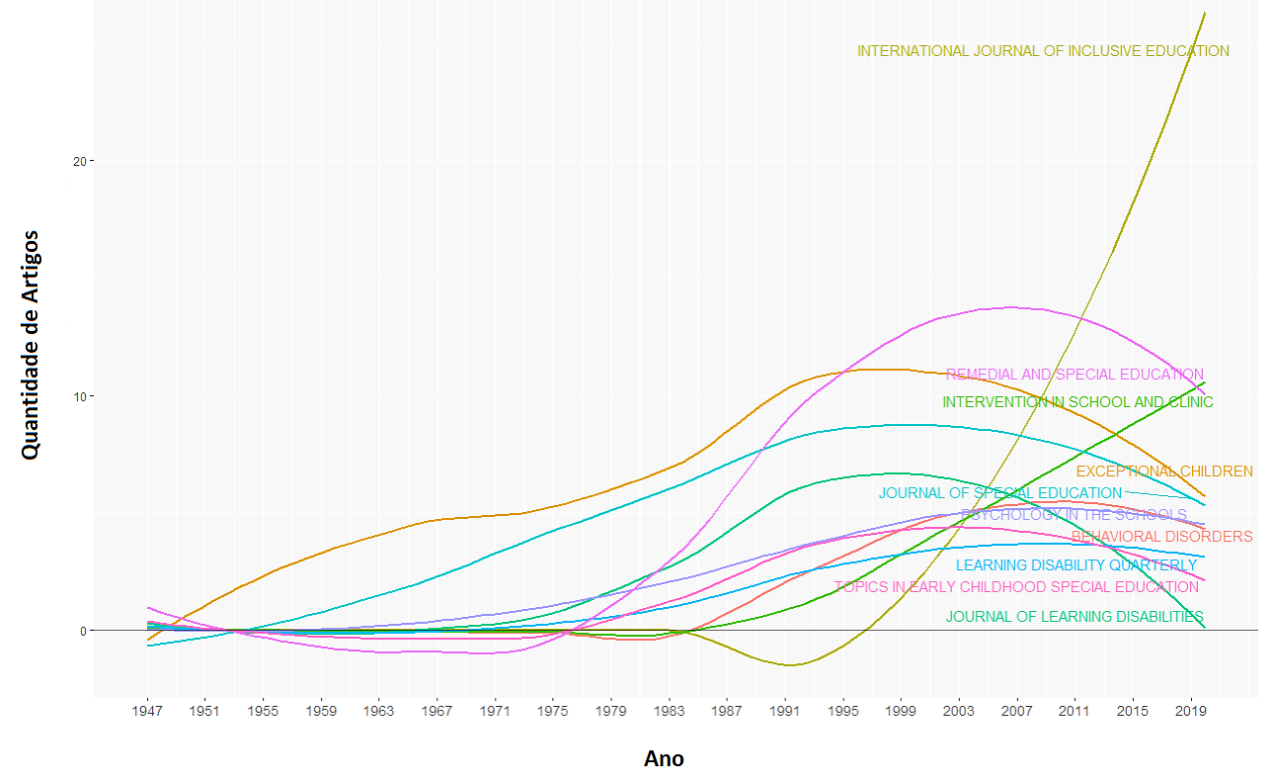

Fonte: Base de Dados WoS (2020).

Com relação aos países com maior número de publicações, apenas 23 possuem mais de 50 publicações no período. A Figura 4 ilustra a distribuição das publicações por todos os países, tendo destaque na legenda os 10 que mais publicaram. Como é possível observar, o Brasil se destaca como o segundo país com maior número de publicações na área. Medições recentes publicadas pela "Nature", uma das revistas científicas mais influentes e de maior impacto do mundo, aponta um crescimento nas produções nacionais, colocando o Brasil na 23ํㅗำ posição global (MAY; BRODY, 2015). No campo do ensino, as 
http://dx.doi.org/10.5902/1984686X44283

produções no país são numericamente significativas, especialmente porque muitos periódicos aceitam propostas de relatos de experiências, as quais descrevem aplicações que incluem diversas propostas práticas para facilitar a aprendizagem de estudantes com NEE.

Ademais, por ser um tópico internacionalmente relevante no campo da educação (HUANG et al., 2019) e, reconhecendo a influência de documentos internacionais na área de EE no Brasil, os quais atuam como um estímulo para a estruturação de pesquisas e mesmo de políticas públicas (PAVEZI; MAINARDES, 2018; RAWOLLE; LINGARD, 2015), é natural que o país siga o ritmo das propostas e esteja entre os que mais produzem na área.

Figura 4 - Países que publicaram mais artigos sobre o tema pesquisado no período de 1947 a 2020 : Estados Unidos, Brasil, Inglaterra, Austrália, Canadá, Espanha, Holanda, Turquia, Finlândia, Alemanha

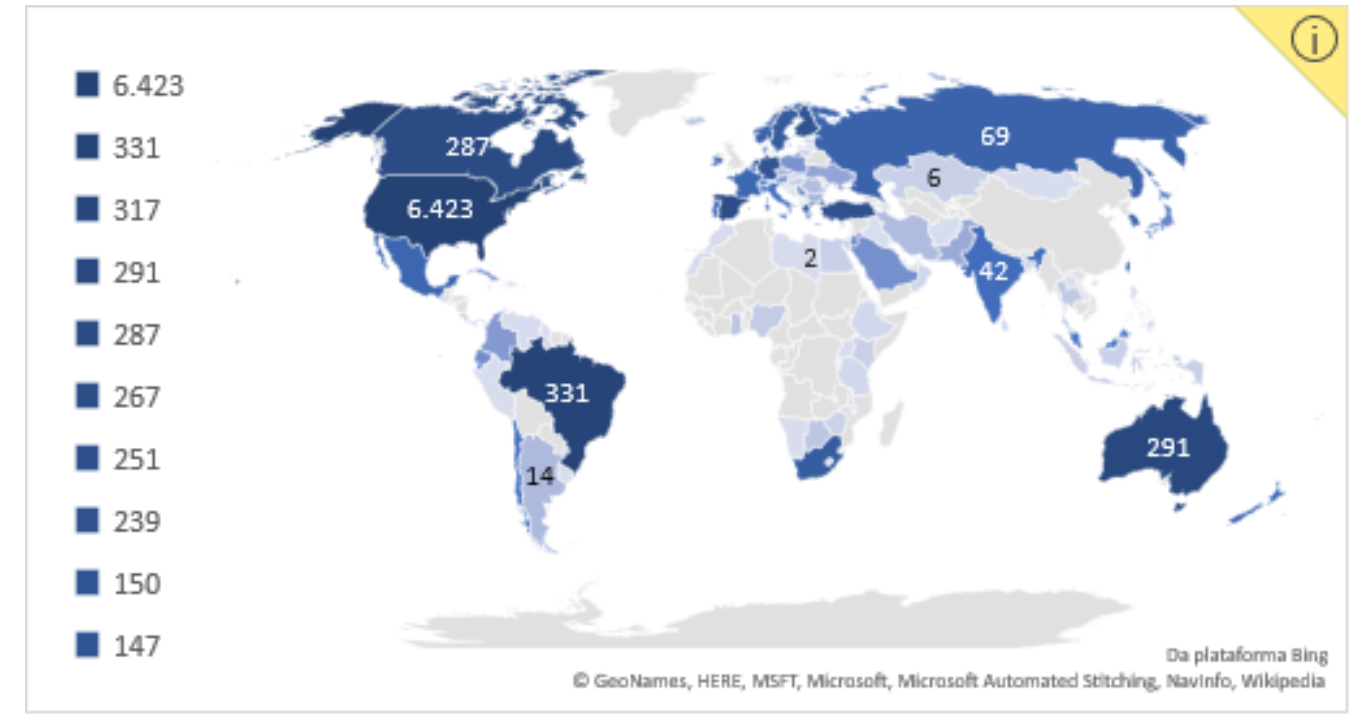

Fonte: Base de Dados WoS (2020).

Entretanto, tem-se percebido que o crescimento numérico expressivo nas publicações, não tem sido acompanhado por um aumento correspondente na internacionalização da ciência no país (RAMOS, 2018). Assim, vale destacar que, embora o Brasil esteja em segundo lugar no número de publicações na área pesquisada, é também o país com menor proporção de cooperação na publicação de artigos com autores de múltiplos países, entre os 10 que mais publicam.

A Finlândia lidera o ranking como o país que mais estabelece cooperação internacional proporcionalmente em pesquisas na área, sendo que $30.71 \%$ das produções são artigos com autores de múltiplos países. O país é seguido no ranking pelo Reino Unido (28.76\%), Alemanha (24.80\%), Canadá (21.82\%), Estados Unidos da América (21.11\%), Austrália (20.26\%), Holanda (18.18\%), Turquia (9.00\%), Espanha (8.51\%) e por último o 
Brasil com apenas $4.97 \%$ das publicações. Sendo que o percentual do Brasil corresponde a colaborações com Portugal (6), Chile (2), Itália (1) e Japão (1).

Outro dado que merece destaque é o das agências financiadoras das pesquisas na área. Nesse caso, as cinco agências que financiam mais estudos são: o Departamento de Saúde dos Estados Unidos - Serviços Humanos (319), o Instituto Nacional de Saúde dos Estados Unidos (286), o Departamento de Educação dos Estados Unidos (145), o Instituto Nacional de Saúde Infantil Desenvolvimento Humano Eunice Kennedy Shriver (119), e o Instituto Nacional de Saúde Mental (104). Como já era esperado, o país que recebe maior investimento, também possui mais pesquisadores atuantes e mais publicações na área. $A$ literatura aponta que a falta de aporte financeiro é um dos desafios tanto para a formação de professores na área da EE com perspectiva inclusiva, quanto para ampliar o públicoalvo a ser atendido (MANZINI, 2018) e, sendo os docentes os principais pesquisadores no Brasil e no mundo, o desafio configura uma limitação para que o país possa avançar no campo do conhecimento.

Com relação aos autores, a totalidade das produções encontradas foi publicada por 19.650 autores, sendo a média de autores por documento de 1.94, e de coautores de 2.89. Os autores com mais publicações no período indicado estão listados na Tabela 2. Como já esperado pelos dados anteriormente apresentados, todos os autores atuam em instituições americanas, sendo a Universidade Virginia e a Universidade Vanderbilt, as que aparecem representadas por dois autores, revelando possíveis líderes de grupos de pesquisa na área.

Tabela 2 - Autores mais relevantes por número de publicações na base

\begin{tabular}{l|l|l|}
\hline \multicolumn{1}{c|}{ AUTORES } & \multicolumn{1}{c|}{ INSTITUIÇÃO/PAÍS } & \multicolumn{1}{c}{ № DE } \\
ARTIGOS
\end{tabular}

Fonte: Base de Dados WoS (2020). 
http://dx.doi.org/10.5902/1984686X44283

Ainda com relação aos autores, outro aspecto também relevante a ser analisado é a produção ao longo do tempo. Tal fator permite verificar quais pesquisadores estão despontando atualmente. A Figura 5, indica o volume de publicações ao longo dos anos de nosso estudo para 20 dos autores mais produtivos na área pesquisada. É possível perceber que, embora não figure atualmente entre os autores que mais publicaram na área, Meghan Burke, possui muitos artigos recentes sobre a temática, enquanto pesquisadores como Lynn Fuchs (FUCHS; FUCHS, 2006), Douglas Fuchs (AL OTAIBA; FUCHS, 2006), e Steven Forness (FORNESS, 2011), os quais estão entre os dez que mais publicaram no período pesquisado, possuem poucas produções atuais na área.

Figura 5 - Gráfico ilustrando as publicações dos 20 autores mais relevantes ao longo dos anos. Os círculos indicam o volume de produções em anos específicos

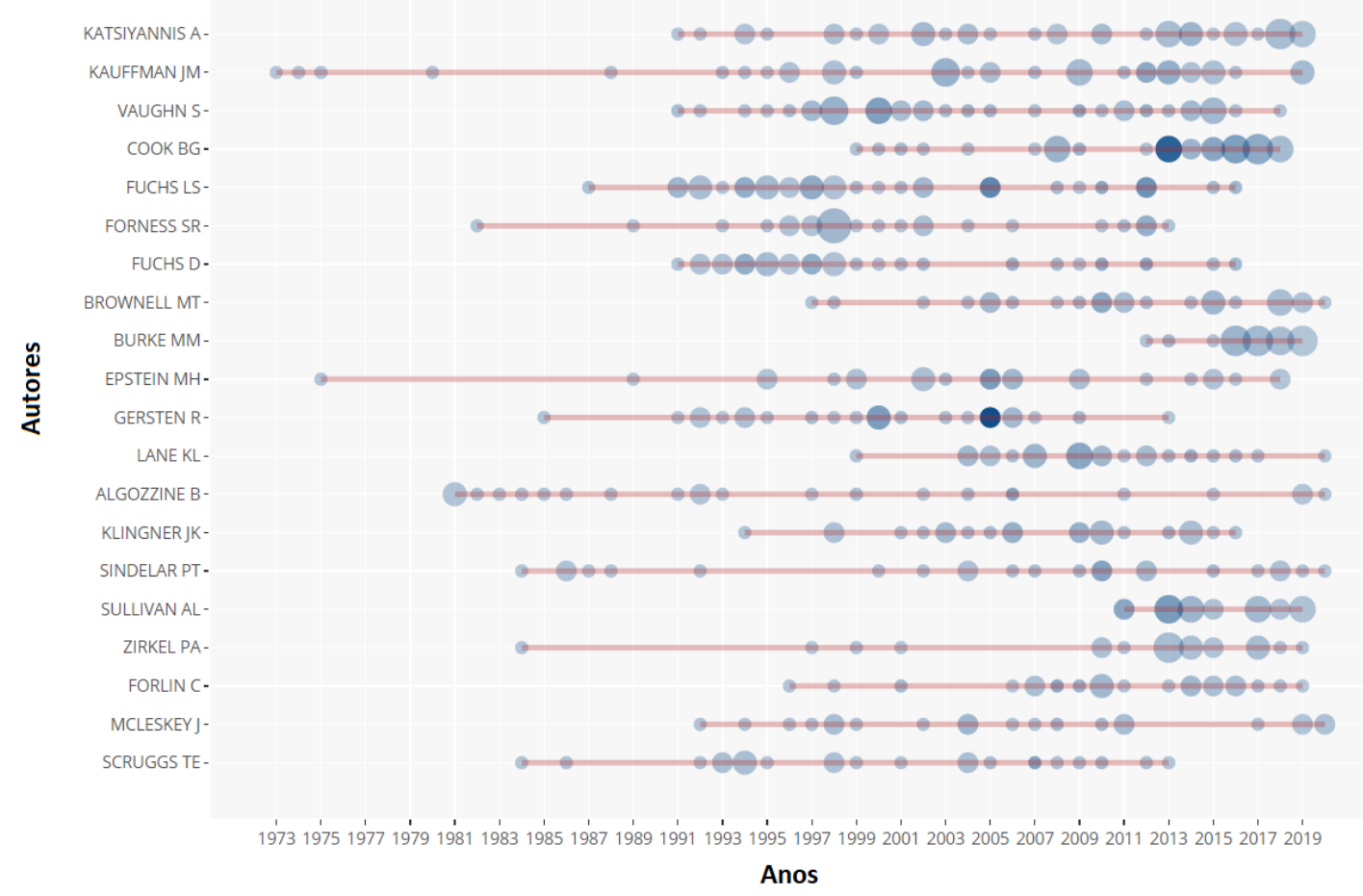

Fonte: Base de Dados WoS (2020).

Reforça-se que, embora os autores indicados na tabela 2 e na figura 5 representem individualmente uma produção considerável na área, algumas instituições despontam como as que possuem mais publicações com pesquisadores envolvidos ao longo do período, são elas: Universidade Estadual da Flórida (406), Universidade da Carolina do Norte (322), Universidade da Califórnia (300), Sistema de Ensino Superior da Pensilvânia Commonwealth (235), e a Universidade Vanderbilt (232). 
http://dx.doi.org/10.5902/1984686X44283

Tais dados possuem implicações para 1) pesquisadores da área, os quais podem encontrar instituições e autores para fortalecimento de grupos de pesquisa, 2) estudantes que tenham interesse em uma especialização na área, visto que podem estabelecer contato com possíveis orientadores, e 3) docentes que busquem estágio pós-doutoral, ou mesmo interessados em ler pesquisas de autores especialistas na área.

Ainda nessa linha, outro dado que merece destaque são as redes de colaboração entre os autores, estas são apresentadas na Figura 6. Somente os 50 autores com mais publicações no conjunto de dados foram considerados (acima de 15 artigos no período). Além disso, na imagem foram mantidos somente autores que possuíam 1 ou mais conexões com os demais. Ressalta-se que o tamanho dos retângulos na figura faz referência à quantidade de publicações de cada autor individualmente, assim, quanto maiores as formas, maior o número de artigos publicados na área. Vale ressaltar que, autores sem vínculos com outros no conjunto foram excluídos do mapa, totalizando 35 autores representados. Cada um dos clusters representados pode ser interpretado como um grupo de pesquisa relativamente formal, composto por um número variável de autores que foram coautores. Ressalta-se que podem ser expostos também colaboradores eventuais.

As redes estabelecidas dão destaque às pesquisadoras Sharon Vaughn e Mary Brownell, mais ao centro. A Dr. ${ }^{a}$ Vaughn foi editora-chefe do Journal of Learning Disabilities e co-editora do Learning Disabilities Research and Practice. Em seu perfil na Universidade do Texas, é possível identificar que a docente é autora de mais de 35 livros, 250 artigos e 65 capítulos que abordam questões relacionadas à pesquisa e prática com estudantes com NEE, investigando intervenções eficazes para estudantes com dificuldades na leitura e escrita da língua inglesa. Já a Dr. a Brownell, é Professora de EE da Universidade da Flórida e Diretora da Colaboração para o Desenvolvimento, Responsabilidade e Reforma de Educadores Eficientes, destinado a melhorar a preparação de professores e líderes trabalhando com alunos com deficiência.

No cluster laranja destacam-se James M. Kauffman, da Universidade Virginia, e Steven R. Forness da Universidade da Califórnia. O primeiro é professor emérito na área de educação no departamento de EE, enquanto o segundo é psicólogo e realiza pesquisas no campo de distúrbios emocionais em crianças, seu principal interesse é a detecção precoce e elegibilidade de crianças com transtornos psiquiátricos para serviços de EE. Ambos possuem colaborações desde 1993, sendo a mais recente, sobre questões 
relacionadas ao acesso e à prevalência cumulativa de crianças com desordens emocionais ou comportamentais nos ambientes de ensino (FORNESS et al., 2012).

Outro grupo em destaque com muitos colaboradores, é o liderado por Marshalyn Yeargin-Allsopp, médica epidemiologista e chefe do ramo de deficiências no desenvolvimento do Centro de Controle e Prevenção de Doenças, onde trabalha desde 1981. A pesquisa de Yeargin-Allsopp concentra-se principalmente na epidemiologia do autismo e outras deficiências, como a paralisia cerebral, especialmente em áreas urbanas. O trabalho mais recente com os colaboradores indicados no cluster azul discorre sobre a prevalência de transtorno do espectro do Autismo em Crianças de 8 Anos nos Estados Unidos (BAIO et al., 2014).

Figura 6 - Rede de colaboração entre os 35 autores que mais publicaram. Imagem obtida por meio do software biblioshiny (versão on-line do pacote Bibliometrix)

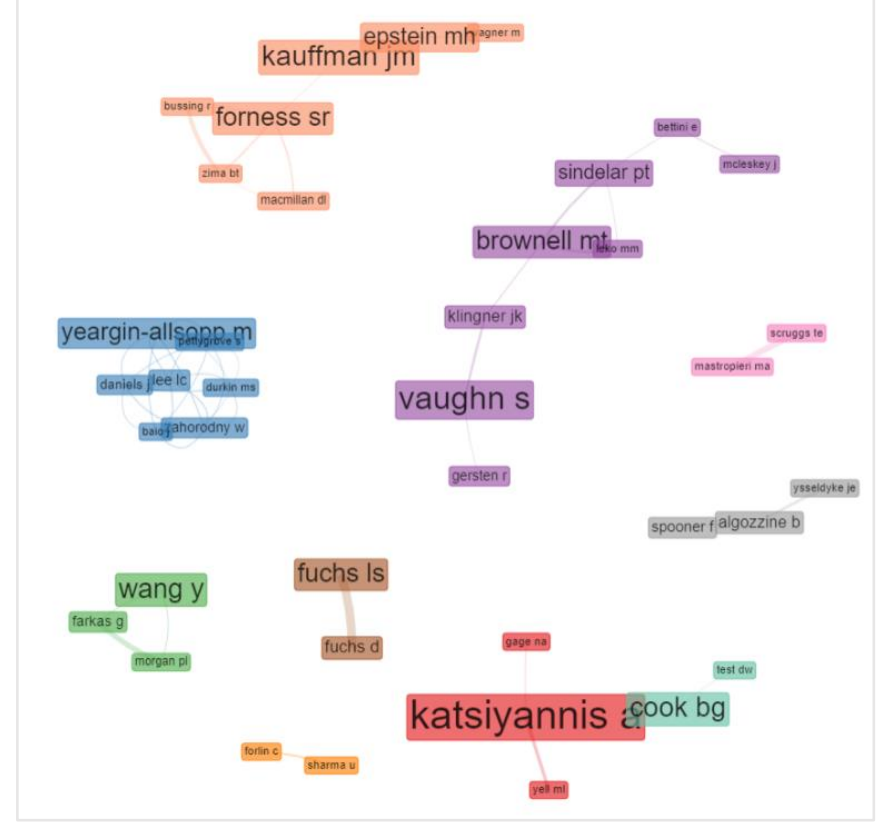

Fonte: Base de Dados WoS (2020).

Por fim, outro grupo que se destaca, embora com menos ligações, é o liderado por Antonis Katsiyannis, autor que mais produziu na área ao longo dos anos. Atualmente, Katsiyannis atua como professor de EE na Universidade de Clemsom, e está envolvido ativamente no campo de distúrbios comportamentais, atuando em conselhos nacionais nos Estados Unidos, inclusive como presidente do Conselho de Crianças com Transtornos Comportamentais. As publicações mais recentes com os colaboradores indicados no cluster vermelho são: uma revisão das intervenções em resposta ao comportamento positivo como estrutura para reduzir exclusões disciplinares (GAGE; WHITFORD; 
http://dx.doi.org/10.5902/1984686X44283

KATSIYANNIS, 2018) e um artigo que examina o progresso e os desafios relacionados ao desenvolvimento de políticas federais para estudantes com distúrbios emocionais e comportamentais, de modo a oferecer recomendações para ajudar a orientar o desenvolvimento futuro de políticas públicas na área (FREEMAN et al., 2018).

Com relação às redes de cocitação, foram estruturados os clusters da figura 7 , na qual os 40 trabalhos mais citados, com um mínimo de cinco conexões entre eles, foram selecionados. Como o número de sobreposições dificulta a visualização, foram utilizados apenas os 40 trabalhos mais citados para que fosse possível identificar as principais obras. Cinco clusters foram bem definidos, sendo que os trabalhos mais citados aparecem em caixas maiores. A seguir, faremos uma síntese dos trabalhos que mais se destacam em cada cluster, revelando o possível tema direcionador destes agrupamentos.

O cluster laranja destaca o trabalho de Dunn (1968). Considerado um clássico na EE (MCLESKEY, 2004), o manuscrito forneceu várias razões para mudar os serviços oferecidos a alunos com deficiência intelectual leve, incluindo problemas com o agrupamento homogêneo desses alunos em turmas separadas, a super-representação de estudantes de grupos minoritários e / ou baixos níveis socioeconômicos nessas classes separadas e a falta de eficácia demonstrada na segregação destes alunos. Além disso, este artigo serviu como catalisador para o movimento de integração e lançou as bases para o estabelecimento de leis voltadas para a inclusão de alunos com NEE.

No cluster azul o trabalho de Brantlinger et al., (2005) aparece em destaque e apresenta indicadores de qualidade para avaliação da pesquisa qualitativa na área da EE. Os autores afirmam que, embora a pesquisa qualitativa não seja conduzida para fins de generalização, estudos qualitativos podem produzir evidências cientificamente sólidas que servem como alicerce para a proposição de políticas e práticas, a partir de evidências baseadas na exploração de contextos específicos e de indivíduos particulares.

No cluster vermelho o trabalho de Avramidis e Norwich (2002) aparece em destaque e avalia as atitudes de professores em relação à integração / inclusão. As análises mostraram evidências de atitudes positivas, mas fortemente influenciadas pela natureza e gravidade da condição incapacitante apresentada pelo estudante. Além disso, variáveis relacionadas ao ambiente educacional, como a disponibilidade de apoio físico e humano, foram consistentemente associadas a atitudes mais favoráveis em relação à inclusão.

O cluster roxo é o menor e apresenta com maior destaque o artigo mais citado na área, o de Horner et al. (2005). Neste, os autores apresentam critérios para definir se uma 
prática será identificada como baseada em evidências na pesquisa com sujeito único. Dada a relevância que as práticas baseadas em evidências (PBE) começaram a adquirir na $E E$ (ODOM et al., 2005), o artigo revela primeiros esforços direcionados no sentido de obter parâmetros para definir tais práticas.

Figura 7 - Rede de cocitação revelando clusters bem estabelecidos com relação às citações

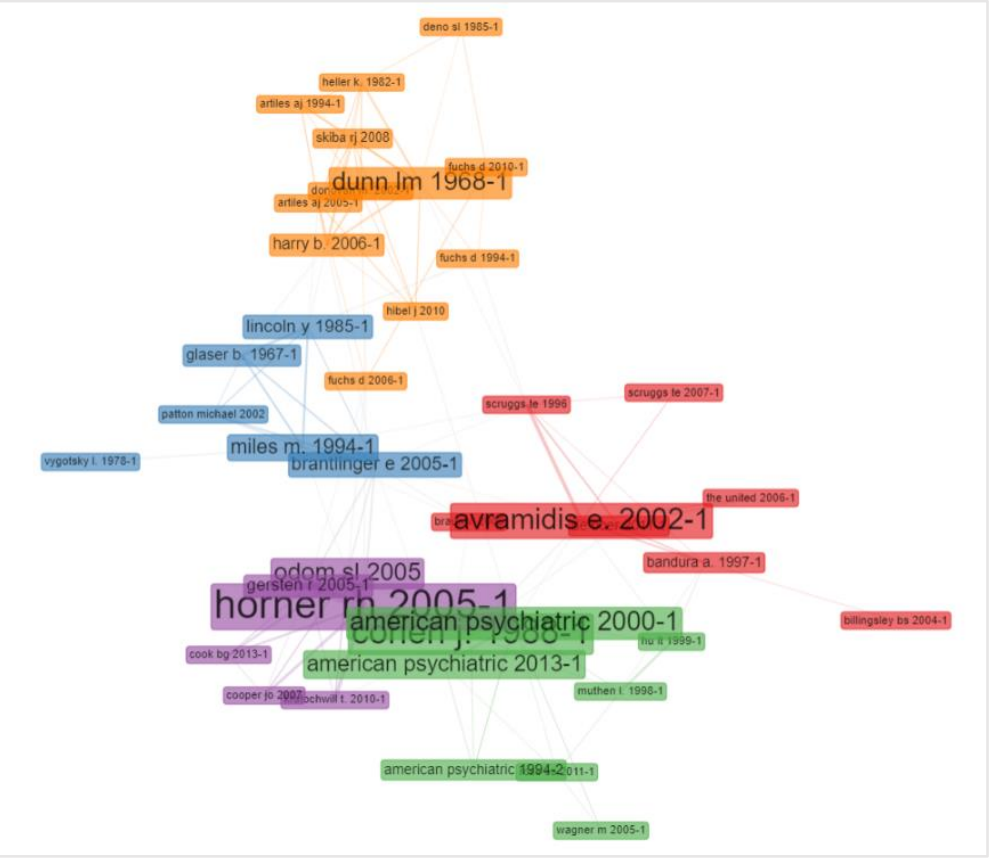

Fonte: Base de Dados WoS (2020).

Por fim o cluster verde aponta as edições de 2000 e 2013 do Manual Diagnóstico e Estatístico de Transtornos Mentais da Associação Americana de Psiquiatria, como os mais citados. Nos Estados Unidos, o Manual serve como principal autoridade para diagnósticos psiquiátricos, além disso, as recomendações de tratamento, bem como o pagamento pelos prestadores de serviços de saúde, geralmente são determinadas pelas classificações do manual (WAKEFIELD, 2013).

\section{Análise dos $\mathbf{2 7}$ artigos selecionados para a metassíntese qualitativa}

Dos 27 artigos selecionados, ao agrupá-los por aspectos metodológicos e objetivos de pesquisa, foi possível identificar que 10 deles descrevem pesquisas empíricas ou de campo, enquanto os demais 17 são artigos de revisão. Discorreremos a seguir em relação ao primeiro grupo de artigos. Apenas um dos artigos fichados menciona a aplicação de recursos associados à tecnologia, por meio do uso de um aplicativo móvel para apoiar alunos com NEE (FERNÁNDEZ-LÓPEZ et al., 2013). No trabalho, o uso da plataforma de 
http://dx.doi.org/10.5902/1984686X44283

aprendizado esteve associado a efeitos positivos no desenvolvimento de habilidades de aprendizagem, oferecendo aos estudantes com NEE a oportunidade de realizar exercícios que antes não eram acessíveis a eles. Além disso, os autores apontam que o uso de dispositivos eletrônicos e conteúdos multimídia aumentou o interesse pelo aprendizado e a interação.

Pesquisas atuais concordam com o exposto, demonstrando que a aprendizagem móvel, usando smartphones e tablets em particular, pode fornecer soluções alternativas na EE como ferramentas de tecnologia assistiva em ambientes de aprendizagem formais e informais (ISMAILI; IBRAHIMI, 2016; OK et al., 2015).

Com relação à outras estratégias apresentadas nas pesquisas de campo e empíricas, estas envolviam: 1) análise da relação entre memória de trabalho e desempenho de leitura em crianças com NEE (DAHLIN, 2011), 2) identificar as características dos alunos que preveem com confiabilidade a capacidade de resposta a intervenções precoces de alfabetização (AL OTAIBA; FUCHS, 2006), 3) avaliar os efeitos de uma intervenção intensiva de leitura terciária, envolvendo habilidades de decodificação e fluência em estudantes com NEE (DENTON et al., 2006), 4) examinar a eficácia do programa educacional individualizado para ensinar habilidades a estudantes (MARTIN et al., 2006), 5) comparar dois programas instrucionais voltados para melhorar habilidades de consciência e decodificação fonêmica, para crianças com graves dificuldades de leitura (TORGESEN et al., 2001), 6) análise de fatores preditivos de melhores resultados na graduação e a colocação em vagas de empregos por estudantes com deficiência (BENZ; LINDSTROM; YOVANOFF, 2000), e 7) analisar o efeito de elogios específicos do comportamento a alunos com distúrbios emocionais e comportamentais (SUTHERLAND; WEHBY; COPELAND, 2000).

Tendo em vista o objetivo da análise, do conjunto de pesquisas acima pontuado, merecem destaque as proposições que demonstram a eficácia dos programas educacionais individualizados (do inglês Individualized Education Program - IEP) (MARTIN et al., 2006), a análise de fatores preditivos de melhores resultados de estudantes com NEE (BENZ; LINDSTROM; YOVANOFF, 2000), e a pesquisa que descreve o efeito de elogios ao comportamento de estudantes com distúrbios emocionais e comportamentais (SUTHERLAND; WEHBY; COPELAND, 2000). Todas essas propostas podem ser aplicadas em diversos contextos de ensino, não sendo restritas a uma disciplina ou conteúdo específicos. No caso do IEP, pesquisas mais recentes demonstram que sua 
elaboração e aplicação pode ser uma estratégia efetiva para nortear o planejamento e a organização curricular, além de impulsionar o desenvolvimento social e acadêmico de estudantes com NEE (GLAT et al., 2012; LIMA; FERREIRA; SILVA, 2018).

$\mathrm{Na}$ análise de fatores preditivos dos melhores resultados de estudantes com NEE, Benz e colaboradores (2000) corroboram o exposto, visto que apontam que a individualização das metas dos alunos e a atenção personalizada dos membros da equipe institucional foram altamente valorizados pelos participantes que obtiveram melhores resultados. Tais análises fornecem implicações concretas para a prática e a política com estudantes com NEE.

Com relação ao poder do elogio, pesquisas reportam que o elogio do professor é uma estratégia eficaz para diminuir o comportamento perturbador dos alunos, e que, em geral, estudantes com problemas de comportamento recebem menos elogios do que seus colegas, apesar das evidências empíricas que apoiam o uso da estratégia para melhorar os resultados dos estudantes (FLORESS et al., 2017; SWEIGART et al., 2016). A subutilização de uma estratégia tão simples, pode ocorrer pelo desconhecimento de seu potencial e pela ausência de estratégias de feedback, também muito relevantes no processo educacional (SWEIGART et al., 2016).

Por fim, as duas últimas pesquisas (empíricas / de campo) analisadas buscaram averiguar: 1) as perspectivas dos professores da EE sobre a pesquisa educacional na área e as maneiras pelas quais novas práticas são introduzidas nas escolas dos professoresalvo (BOARDMAN et al., 2005); e 2) a frequência com que PBE estão envolvidas na educação de alunos com deficiência (BURNS; YSSELDYKE, 2009). Apesar de o foco dos manuscritos não ser propriamente a aplicação, avaliação ou descrição de práticas de ensino, optou-se por mantê-los justamente por apresentarem uma avaliação por parte dos docentes e equipe de apoio pedagógico de mais de 300 escolas, revelando que práticas de ensino com pouco ou nenhum suporte empírico são usadas com frequência na EE, demonstrando que a área não está imune à lacuna entre pesquisa e prática, reconhecidamente presente na educação geral.

Nesse sentido, é válido ressaltar que na análise das demais 17 pesquisas (artigos de revisão) levantados no processo de seleção, foi possível perceber que 7 delas discorrem diretamente sobre PBE e 8 tangenciam o assunto. A seguir estarão descritos pontos relevantes e convergentes levantados por cada um dos artigos. 
http://dx.doi.org/10.5902/1984686X44283

Cook e Odom (2013) revelam que a busca por PBE se originou no campo da medicina com a intenção de usar a literatura para fundamentar e atualizar decisões práticas. Odom e colaboradores (2005), afirmam que, seguindo a mesma linha, tanto a educação geral quanto a especial propuseram a adoção de evidências científicas como base para a seleção de práticas de ensino de sucesso. Contudo, o intenso interesse dos pesquisadores conduziu-os também à importante etapa de definição de quais seriam os critérios para assumir se um determinado método é, de fato, uma PBE.

Embora os padrões específicos possam variar, os artigos analisados revelam as diretrizes típicas para que uma prática de ensino seja considerada PBE: ela deve ser apoiada por estudos múltiplos, de alta qualidade, experimentais ou quase-experimentais (incluindo pesquisas de caso único), demonstrando em detalhes como ela foi conduzida e revelando resultados com impacto significativo para o estudantes com NEE (COOK; ODOM, 2013; COOK; TANKERSLEY; LANDRUM, 2009; HORNER et al., 2005; GERSTEN, et al., 2005; ODOM, et al., 2005).

Em detalhes, no artigo mais citado da área, escrito por Horner e colaboradores (2005), os autores apresentam que na pesquisa de um único sujeito, para que uma prática seja identificada como baseada em evidências: o método deve ser descrito com precisão suficiente para que outros possam replicá-lo; incluindo o contexto, as condições específicas, quais seriam os indivíduos qualificados para aplicá-la, o público-alvo para o qual se espera que a prática seja eficaz, as variáveis e resultados específicos.

Segundo Cook e Odom (2013), estabelecer um processo para identificar PBE na EE foi um avanço significativo para o campo, pois permitiu a estruturação de programas educacionais mais eficazes, com resultados mais objetivos para os alunos com deficiência. No entanto, os mesmos autores reforçam que 1) apenas porque uma prática não é considerada uma PBE não necessariamente significa que é ineficaz, e 2) nem todas as PBE funcionarão para todos os estudantes de igual maneira, é preciso considerar o contexto e os indivíduos envolvidos, essa é a realidade na educação.

Ademais, nos artigos também foi possível reconhecer que mesmo com critérios, não há consenso exato e existem abordagens diferentes para identificar e categorizar as práticas. Horner et al. (2005), por exemplo, propuseram uma categorização dicotômica, ou seja, PBE ou não, já Gersten et al., (2005) propuseram uma classificação em três níveis, organizando as propostas em: baseadas em evidências, promissoras e não baseadas em evidências. 
A identificação sistemática de PBE tem grande potencial para melhorar a vida de crianças e jovens com NEE, mas somente a identificação é insuficiente, é necessário a implementação e o apoio para seu uso em sala de aula (ODOM, 2009). A pesquisa de Landrum, Tankersley e Kauffman (2003) mostrou que muitas das práticas eficazes não são implementadas rotineiramente, e que, em geral, os professores não usam intervenções eficazes, fato corroborado por pesquisas mais atuais (LAWLOR et al., 2019).

Contudo, estudiosos da área revelam que a intenção não é que docentes sejam obrigatoriamente orientados sobre quando e como podem ou não usar práticas particulares de ensino, mas que ao conhecer a proposta, o profissional busque as melhores formas de aplicar em seu contexto em busca de bons resultados de aprendizagem para alunos com NEE (COOK et al., 2009; COOK, ODOM, 2013).

Como dito anteriormente, embora o tema central dos 7 artigos de revisão fossem as PBE, 8 dos 10 manuscritos restantes também tangenciaram o tema, descrevendo estratégias mais específicas que são consideradas PBE. Bruder (2010) ao abordar o campo da intervenção na primeira infância para crianças com deficiências ou atrasos, apresenta, dentre as recomendações, o desenvolvimento e a instituição de PBE, bem como a implementação de sistemas abrangentes de desenvolvimento profissional para o trabalho com esse público.

Browder et al. (2009), por sua vez, utilizam o que eles chamam de "time delay" como uma PBE para o ensino de símbolos para alunos com deficiências moderadas e graves. Neste procedimento, o professor apresenta a palavra com um modelo imediato da resposta e dá ao aluno a oportunidade de repetir. Em testes subsequentes, a fala do professor é adiada por alguns segundos para que o aluno possa antecipar a resposta correta. Os resultados mostraram evidências de que o uso do atraso no tempo é eficaz para ensinar aos alunos com deficiência visual moderada.

O artigo de Sutherland et al., (2008) trata sobre alunos com transtornos emocionais ou comportamentais e detalha: 1) maneiras pelas quais os comportamentos instrucionais dos professores e os contextos em sala de aula podem contribuir para os problemas de aprendizagem e o comportamento dos alunos e 2) procedimentos de avaliação úteis para medir variáveis contextuais em sala de aula. Os autores sugerem que reduzir o comportamento perturbador pode ser menos importante para os resultados acadêmicos do que aumentar o envolvimento na tarefa e a resposta ativa. 
Bellini e Akullian (2007) examinaram a eficácia das intervenções de modelagem e auto modelagem de vídeo em crianças e adolescentes com transtornos do espectro autista. Os resultados sugerem que ambas estratégias são eficazes para abordar habilidades de comunicação social e comportamentais em crianças e adolescentes com autismo, e que as habilidades adquiridas são mantidas ao longo do tempo. Os autores concluem afirmando que as estratégias atendem aos critérios de designação como uma PBE.

No artigo de 2006, Browder et al. apresentam resultados de uma revisão de 128 estudos sobre o ensino de leitura para indivíduos com deficiências cognitivas. Os revisores consideraram não apenas o número de estudos, mas os demais indicadores propostos para identificar PBE. Eles destacaram que, ao aplicar os critérios, ficou evidente que a qualidade da pesquisa em EE melhorou com o tempo, especialmente em termos de descrição da implementação e da fidelidade processual.

Como resultados, os autores apontaram que compartilhar histórias é uma maneira eficaz de promover habilidades de leitura, como compreensão, vocabulário e fluência em um contexto significativo. Uma segunda maneira de construir uma intervenção de leitura é o estímulo sistemático com muitas oportunidades para o aluno participar e praticar o conhecimento respondendo a interações sugeridas pelo instrutor.

Conroy, Dunlap e Clarke, (2005) examinaram artigos publicados entre 1984 e 2003 em 23 periódicos revisados por pares. Os resultados indicaram uma tendência crescente de pesquisa utilizando intervenções comportamentais positivas com crianças pequenas que demonstram comportamentos desafiadores. A maioria dos estudos empregou metodologias de pesquisa de sujeito único para examinar intervenções multicomponentes, instrucionais ou baseadas em funções.

O artigo de Deno (2003) trata sobre a Medição Baseada em Currículo, uma abordagem para avaliar o crescimento dos alunos em habilidades básicas na EE. A revisão demonstra que o método pode ser usado efetivamente para reunir dados de desempenho e competências dos alunos e apoiar uma ampla gama de decisões educacionais.

Apesar de não tratar propriamente de PBE, o artigo de Vaughn, Gersten e Chard (2000) apresenta propostas que se encaixam em diversos contextos de ensino de alunos com NEE, dentre elas: a importância do controle no nível de dificuldade e volume das tarefas, dar instruções visíveis e explícitas para cada passo e feedback contínuo aos estudantes com NEE, usar recursos tecnológicos quando possível, propor atividades focadas na construção sistemática de habilidades, trabalhar com grupos pequenos de no 
máximo seis estudantes, estimular os alunos a desenharem planos de ação para guiarem seus objetivos de aprendizagem, utilizar procedimentos que promovam o pensamento em voz alta e o diálogo interativo entre professor - estudante e entre os pares.

A revisão de Gersten e Baker (2000) aponta a escassez de estudos experimentais, à época, e Brantlinger et al., (2005), apresentam indicadores de qualidade para avaliação da pesquisa qualitativa na área da EE. Nesta, os autores afirmam que, embora a pesquisa qualitativa não seja conduzida para fins de generalização, tais estudos podem produzir evidências cientificamente sólidas e úteis para direcionar políticas e práticas.

O objetivo final da metassíntese qualitativa é justamente apresentar um quadro conciso, convergente e sintético das soluções encontradas na produção analisada. Assim como os autores supracitados não reivindicam que possam oferecer prescrições universais para a prática, a presente metassíntese também não pretende oferecer. Contudo, como apontado nas pesquisas referenciadas, a maior parte dos professores não faz uso das PBE e de muitos métodos funcionais e viáveis em seus contextos, por falta de conhecimento.

Assim, sugere-se a seguir algumas proposições combinadas a partir dos trabalhos analisados, as quais podem ser funcionais para o ensino na área da EE: 1) o estabelecimento de um plano educacional individualizado e de um currículo que tenha como foco as competências e não limitações dos estudantes com NEE, permitindo, sempre que possível, que estes construam planos de ação, revelando onde, quando e como usar uma estratégia em particular para o aprendizado, 2) que haja atenção personalizada da equipedidático pedagógica, com fornecimento de feedback sempre que possível, considerando o poder do elogio como uma das estratégias relevantes para o ensino, 3) utilizar métodos com instruções diretas e explícitas, voltados para o estímulo da memória e/ou resposta ativa, os quais permitam interatividade entre os pares, e 4) buscar PBE aplicáveis ao contexto e público a ser atendido, tendo em mente que a dificuldade da proposta deve ser moderada de modo a manter a persistência dos estudantes para alcance dos objetivos de aprendizagem.

\section{Conclusões}

Como foi possível identificar, existem muitas publicações disponíveis na área de ensino voltado para a EE. Apesar do foco considerável das publicações mais citadas concentrar-se na lacuna pesquisa-prática e na identificação de PBE como proposta para 
solucionar a lacuna, existem poucas evidências sugerindo que essa lacuna tenha sido significativamente reduzida (COOK; ODOM, 2013).

Se o docente pretende aplicar propostas para estudantes com NEE, é muito importante que averigue na produção científica as que se encaixam melhor com seu contexto e as especificidades do seu alunado, de modo a propor práticas que já tenham demonstrado resultados positivos e baseiem-se em aplicações com metodologias consolidadas.

A metodologia proposta no presente artigo permitiu não somente um caminho estratégico para encontrar práticas nessa linha, como identificar os principais autores, países e instituições que propõem tais métodos. Os resultados encontrados podem ter implicações no sentido de guiar 1) Docentes que atuam com estudantes com NEE em suas atividades cotidianas, 2) Estudantes de pós-graduação que tenham interesse em especializar-se na área, 3) Pesquisadores que atuam com a temática, de modo que estes estabeleçam redes de colaborações objetivas e produtivas com colegas com propostas proeminentes na área em outros países.

Além disso, tendo em vista as diretrizes típicas para identificação de uma PBE, pesquisas que unam a bibliometria e a metassíntese qualitativa mostram-se úteis na identificação das propostas, visto que permitem a realização de uma revisão sistemática revelando resultados com impacto significativo para os estudantes com NEE.

Apesar de limitada a um conjunto específico de artigos em uma base de dados, os manuscritos foram criteriosamente selecionados e possuem impacto relevante na área de estudo, sendo os mais citados ao longo dos últimos 20 anos. Além do fato de serem os mais citados, ressalta-se que, por serem em sua maioria artigos de revisão, os trabalhos oferecem uma súmula relevante a respeito do que tem sido pesquisado na área nos últimos anos.

Além da limitação acima apresentada, as autoras reconhecem que é impossível esgotar a análise no campo da EE e inclusiva, mas o presente artigo oferece um direcionamento criteriosamente estabelecido. $\mathrm{E}$, tendo em vista a persistente lacuna entre a pesquisa em educação e a aplicação em sala de aula, propostas como a descrita no presente artigo devem ser fomentadas e divulgadas, de modo a incentivar a aplicação de práticas instrucionais baseadas em evidências, e revelar um caminho seguro para encontrar pesquisas com impacto e rigor. 
http://dx.doi.org/10.5902/1984686X44283

\section{Referências}

AINSCOW, Mel. Understanding the development of inclusive education system. Electronic Journal of Research in Educational Psychology. Manchester, v. 3, n. 7, p. 5-20, dez. 2005.

AINSCOW, Mel; SLEE, Roger; BEST, Marnie. Editorial: the Salamanca Statement: 25 years. International Journal of Inclusive Education, Londres, v. 23, n. 7-8, p. 671-676, jun. 2019.

AL OTAIBA, Stephanie, FUCHS, Douglas. Who Are the Young Children for Whom Best Practices in Reading Are Ineffective? An Experimental and Longitudinal Study. Journal of Learning Disabilities, [S.I.], v. 39, n. 5, p. 414-431, set. 2006.

ALENCAR, Edvonete Souza de; ALMOULOUD, Saddo Ag. A Metodologia de Pesquisa: Metassíntese Qualitativa. Revista Reflexão e Ação, Santa Cruz do Sul, v. 25, n. 3, p. 204220, Set./Dez. 2017.

ALKHATEEB, Jamal M.; HADIDI, Muna S.; ALKHATEEB, Amal. Inclusion of Children with Developmental Disabilities in Arab Countries: A Review of the Research Literature From 1990 to 2014. Research in Developmental Disabilities, [S.I.], v. 49, n. 50, p. 60-75, mar. 2016.

AMOR, Antonio M. et al. International Perspectives and Trends in Research on Inclusive Education: A Systematic Review. International Journal of Inclusive Education, Londres, v. 23, n. 12, p. 1277-1295, 2019.

ARIA, Massimo; CURCCURULLO, Corrado. Bibliometrix: an R-tool for comprehensive science mapping analysis. Jornal of Informetrics, [S.I.], v. 11, n. 4, p. 959-975, nov. 2017.

AVRAMIDIS, Elias; NORWICH, Brahm. Teachers' attitudes towards integration / inclusion: a review of the literature. European Journal of Special Needs Education, [S.I.], v. 17, n. 2, p. 129-147, out. 2002.

BAIO, Jon et al. Prevalence of Autism Spectrum Disorder Among Children Aged 8 Years Autism and Developmental Disabilities Monitoring Network, 11 Sites, United States, 2014. Surveillance Summaries, [S.I.], v. 7, n. 6, p. 1-23, abr. 2018.

BELLINI, Scott; AKULLIAN, Jennifer. A Meta-Analysis of Video Modeling and Video SelfModeling Interventions for Children and Adolescents with Autism Spectrum Disorders.

Exceptional Children, [S.I.], v. 73, n. 3, p. 264-287, abr. 2007.

BENZ, Michael R.; LINDSTROM, Lauren; YOVANOFF, Paul. Improving Graduation and Employment Outcomes of Students with Disabilities: Predictive Factors and Student Perspectives. Exceptional Children, [S.I.], v. 66, n. 4, p. 509-529, jun. 2000.

BOARDMAN, Alison Gould et al. Special Education Teachers' Views of Research-Based Practices. The Journal of Special Education, Austin, v. 39, n. 3, p. 168-180, nov. 2005. 
BOOTH, Tony; AINSCOW, Mel. Index for inclusion. Developing learning and participation in schools ( $3^{\circ}$ ed). Bristol: CSIE, 2013.

BRANTLINGER, Ellen, et al. Qualitative Studies in Special Education. Exceptional Children, [S.I.], v. 71, n. 2, p. 195-207, nov. 2005.

BRASIL. Resolução CNE/CEB n 2 de 11 de setembro de 2001. Diretrizes Nacionais para a Educação Especial na Educação Básica. Diário Oficial da União, Brasília, 14 de setembro de 2001. Seção 1E, p. 39-40. Brasília: MEC, 2001a. Disponível em: http://portal.mec.gov.br/cne/arquivos/pdf/CEB0201.pdf. Acesso em: 7mai. 2020.

BRASIL. Parecer CNE/CEB no 17/2001. Diretrizes Nacionais para a Educação Especial na Educação Básica. Diário Oficial da União, Brasília, 17 de agosto de 2001, Seção 1, p. 46. Brasília: MEC, 2001b. Disponível em:

http://portal.mec.gov.br/cne/arquivos/pdf/CEB017_2001.pdf. Acesso em: 7mai. 2020.

BRASIL. Parecer CNE/CP no 9/2001. Diretrizes Curriculares Nacionais para a Formação de Professores da Educação Básica, em nível superior, curso de licenciatura, de graduação plena. Diário Oficial da União, Brasília, 18 de janeiro de 2002, Seção 1, p. 31. Brasília: MEC, 2002.

BROWDER, Diane, et al. Research on reading instruction for individuals with significant disabilities. Exceptional Children, [S.I.], v. 72, p. 392-408, jun. 2006.

BROWDER, Diane, et al. Using Time Delay to Teach Literacy to Students with Severe Developmental Disabilities. Exceptional Children, [S.I.], v. 75, n. 3, p. 343-364, abr. 2009.

BRUDER, Mary Beth. Early Childhood Intervention: a promise to children and families for their future. Exceptional children, [S.I.], v. 76, n. 3, p. 339-355, ago. 2010.

BURNS, Matthew K.; YSSELDYKE, James E. Reported prevalence of evidence-based instructional practices in special education. The Journal of Special Education, Austin, v. 43, p. 3-11, abr. 2009.

CASTRO, Felipe González, et al. A Methodology for conducting integrative mixed methods research and data analyses. Journal of Mixed Methods, [S.I.], v. 4, n. 4, p. 342-360, set. 2010. Disponível em:< https://www.ncbi.nlm.nih.gov/pmc/articles/PMC3235529/>. Acesso em: 25 de mar. 2020.

CASTRO, Aldemar Araújo; SACONATO, Humberto; GUIDUGLI, Fabio; CLARK, Otavio Augusto Camara. Curso de revisão sistemática e metanálise [Online]. São Paulo: LEDDIS/UNIFESP; 2002. Disponível em: URL: http://www.virtual.epm.br/cursos/metanalise; acesso em 23 de junho de 2012.

CONROY, Maureen; DUNLAP, Glen; CLARKE, Shelley. A descriptive analysis of positive behavioral intervention research with young children with challenging behavior. Topics in Early Childhood Special Education, [S.I.], v. 25, n. 3, p. 157-166, set. 2005. 
COOK, Bryan G.; SCHIRMER, Barbara. What is special about special education? Overview and analysis. The Journal of Special Education, Austin, v. 37, p. 200-205, nov. 2003.

COOK, Bryan; TANKERSLEY, Melody; LANDRUM, Timothy. Determining Evidence-Based Practices in Special Education. Exceptional children, [S.I.], v. 75, n. 5, p. 365-383, mar. 2009.

COOK, Bryan G.; ODOM, Samuel. L. (2013). Evidence-Based Practices and Implementation Science in Special Education. Exceptional Children, [S.I.], v. 79, n. 3, p. 135-144, 2013.

DAHLIN, Karin I.E. Effects of working memory training on reading in children with special needs. Reading and Writing, [S.I.], v. 24, p. 479-491, mai. 2011.

DE-BOER, Anke; PIJL, Sip Jan; MINNAERT, Alexander. Regular primary school teachers' attitudes towards inclusive education: A review of the literature. International Journal of Inclusive Education, Londres, v. 15, n. 3, p. 331-353, 2011.

DENO, Stanley. Developments in Curriculum-Based Measurement. Journal of Special Education, [S.I.], v. 37, n. 3, p. 184-192, nov. 2003.

DENTON, Carolyn, et al. An Evaluation of Intensive Intervention for Students with Persistent Reading Difficulties. Journal of Learning Disabilities, [S.I.], v. 39, p. 447-66, out. 2006.

DUNN, Lloyd M. Special education for the mildly retarded-is much of it justifiable? Exceptional Children, [S.I.], v. 35, p. 5-22, fev. 1968.

FERNÁNDEZ-LÓPEZ, Álvaro, et al. Mobile learning technology based on iOS devices to support students with special education needs. Computers \& Education, [S.I.], v. 61, p. 77-90, fev. 2013.

FLORESS, Margaret T.; et al. Preschool teachers' use of praise in general, at-risk, and special education classrooms. Psychology in the Schools, [S.I.], v. 54, n. 2, p. 519-531, mar. 2017.

FORNESS, Steven R., et al. Special Education Implications of Point and Cumulative Prevalence for Children with Emotional or Behavioral Disorders. Journal of Emotional and Behavioral Disorders, [S.I.], v. 20, n. 1, p. 4-18, 2011.

FREEMAN, Jennifer, et al. Federal policy on improving outcomes for Students with Emotional and Behavioral Disorders: Past, Present, and Future. Behavioral Disorders, [S.I.], v. 44, n. 2, p. 97-106, nov. 2018.

FUCHS, Douglas; FUCHS Lynn S. Introduction to response to intervention: What, why, and how valid is it? Reading Research Quarterly, [S.I.], v. 41, n. 1, p. 99-99, jan. 2006.

GAGE, Nicholas A.; WHITFORD, Denise K.; KATSIYANNIS, Antonis. A Review of Schoolwide Positive Behavior Interventions and Supports as a Framework for Reducing Disciplinary Exclusions. The Journal of Special Education, Austin, v. 52, n. 3, p. 142-151, mai. 2018. 
GERHARDT, Tatiana Engel, SILVEIRA, Denise Tolfo. (Orgs.). Métodos de Pesquisa. Porto Alegre: Editora UFRGS, 2009.

GERSTEN, Russell; BAKER, Scott. What We Know about Effective Instructional Practices for English-Language Learners. Exceptional Children, [S.I.], v. 66, p. 454-470, jul. 2000.

GERSTEN, Russell, et al. Quality Indicators for Group Experimental and QuasiExperimental Research in Special Education. Exceptional Children, [S.I.], v. 71, n. 2, p. 149-164, dez. 2005.

GLAT, Rosana; et al. Plano educacional individualizado: uma estratégia a ser construída no processo de formação docente. Ciências Humanas e Sociais em Revista, Rio de Janeiro, v. 34, n. 1, p. 79-100, jul. 2012.

HASSAN, Saeed, U., \& HADDAWY, Peter. Analyzing knowledge flows of scientific literature through semantic links: A case study in the field of energy. Scientometrics, [S.I.], v. 103, n.1, p. 33-46, jan. 2015.

HERNÁNDEZ-TORRANO, Daniel; SOMERTON, Michelle; HELMER, Janet. Mapping research on inclusive education since Salamanca Statement: a bibliometric review of the literature over 25 years. International Journal of Inclusive Education, Londres, v. 24, n. 1, mar. 2020.

HORNER, Robert N. et al. The Use of Single-Subject Research to Identify Evidence-Based Practice in Special Education. Exceptional Children, [S.I.], v. 71, p. 165-179, 2005.

HUANG, Cui; YANG, Chao; WANG, Shutao; WU, Wei; SU, Jun; LIANG, Chuying. Evolution of topics in education research: a systematic review using bibliometric analysis.

Educational Review, [S.I.] v. 72, n. 3, p. 281-297, fev. 2019.

ISMAILI, Jalal; IBRAHIMI, EI Houcine Ouazzani. Mobile learning as alternative to assistive technology devices for special needs students. Education and Information Technologies, [S.I.], v. 22, n. 3, p. 883-899, jan. 2016.

MARTIN, James. E., et al. Increasing Student Participation in IEP Meetings: Establishing the Self-Directed IEP as an Evidenced-Based Practice. Exceptional Children, [S.I.], v. 72, n. 3, p. 299-316, abr. 2006.

LANDRUM, Timothy J.; TANKERSLEY, Melody; KAUFFMAN, James M. What Is Special About Special Education for Students with Emotional or Behavioral Disorders? The Journal of Special Education, Austin, v. 37, n. 3, p. 148-156, nov. 2003.

LAWLOR, Jennifer A.; et al. Approaches to measuring use of research evidence in $\mathrm{K}-12$ settings: A systematic review. Educational Research Review, Leuven, v. 27, 218-228, abr. 2019.

LETA, Jacqueline; THIJS, Bart; GLÄNZEL, Wolfgang. A macro-level study of science in Brazil: seven years later. Revista Eletrônica de Biblioteconomia e Ciência da Informação, Florianópolis, v. 18, n. 36, p. 51-66, mai. 2013. 
LILLIS, Theresa; CURRY, Mary Jane. Academic Writing in a Global Context. Abingdon: Routledge, 2010.

LIMA, Letícia Aparecida Alves de; FERREIRA, Ana Eliza Gonçalves; SILVA, Marcus Vinicius Gonçalves da. O plano educacional individualizado: proposta de um método de pesquisa na formação docente. Educação Em Perspectiva, Viçosa, v. 9, n. 1, p. 127-141, abr. 2018

MANZINI, Eduardo José. Política de educação especial: considerações sobre público-alvo, formação de professores e financiamento. Revista on line de Política e Gestão

Educacional, [S.I.], v. 22, n. 2, p. 810-824, dez. 2018.

MATHEUS, Maria Clara Cassuli. Metassíntese qualitativa: desenvolvimento e contribuições para a prática baseada em evidências. Acta Paulista de Enfermagem, São Paulo, v. 22, p. 543-545, abr. 2009.

MARTIN, James, et al. Increasing Student Participation in IEP Meetings: Establishing the Self-Directed IEP as an Evidenced-Based Practice. Exceptional Children, [S.I.], v. 72, p. 299-316, mar. 2006.

MAY, Mike; BRODY, Herb. Nature Index 2015 Global. Nature, [S.I.], 522, S1, jun. 2015. Disponível em: https://www.nature.com/articles/522S1a. Acesso em: 14 mai. 2020.

MCLESKEY, James. Classic Articles in Special Education. Remedial and Special Education, [S.I.], v. 25, n. 2, p. 79-87, mar. 2004.

ODOM, Samuel L. et al. Research in Special Education: Scientific Methods and EvidenceBased Practices. Exceptional Children, [S.I.], v. 71, n. 2, p. 137-148, jan. 2005.

ODOM, Samuel L. The Tie That Binds: Evidence-Based Practice, Implementation Science, and Outcomes for Children. Topics in Early Childhood Special Education, [S.I.], v. 29, n. 1, p. 53-61, dez. 2009.

OK, Min Wook, et al. How to Find Good Apps: an evaluation rubric for instructional apps for teaching students with learning disabilities. Intervention in School and Clinic, [S.I.], v. 51, n. 4, p. 244-252, jun. 2015.

PAVEZI, Marilza; MAINARDES, Jefferson. Análise das Influências de documentos Internacionais na Legislação e Políticas de Educação Especial No Brasil (1990-2015). Revista Interacções, Santarém, v. 49, p. 153-172, jun. 2018.

PAYUMO, Jane, G.; SUTTON, Taurean C. A bibliometric assessment of ASEAN collaboration in plant biotechnology. Scientometrics, [S.I.], v. 103, n. 3, p. 1043-1059, jun. 2015.

PEEBLES, Jodi; MENDAGLIO, Sal. Preparing teachers for inclusive classrooms: Introducing the individual direct experience approach. Learning Landscapes Journal, Quebec, v. 7, n. 2, p. 245-257, abr. 2014. 
RAFOLS, Ismael; et al. On the dominance of quantitative evaluation in "peripheral" countries: auditing research with technologies of distance. Social Science Research Network, [S.I.], p 1-22, ago. 2016.

RAMOS, Milena Yumi. Internacionalização da pós-graduação no Brasil: lógica e mecanismos. Educação e Pesquisa, São Paulo, v. 44, p. 1-22, mai. 2018.

RAVIKUMAR, Sharina, AGRAHARI, Ashutosh; SINGH, Sri Nivas. Mapping the intellectual structure of scientometrics: A co-word analysis of the journal Scientometrics (2005-2010). Scientometrics, [S.I.], v. 102, n. 1, p. 929-955, jan. 2015.

RAWOLLE, Shaun; LINGARD, Bob. Bourdieu and doing policy sociology in education. In: GULSON, Kalervo N.; CLARKE, Matthew; PETERSEN, Eva Bendix (Eds.), Education policy and contemporary theory: implications for research (pp. 15-26). Abingdon: Routledge, 2015.

RIBEIRO, Matheus de Souza Lima, et al. Análise cienciométrica em ecologia de populações: importância e tendências dos últimos 60 anos. Acta Scientiarum Biological Sciences, Maringá, v. 29, n.1, p. 39-47, fev. 2007.

SNELL, Martha E. Applying research to practice: The more pervasive problem? Research and practice for persons with severe disabilities, Wyoming, v. 28, p. 143-147, set. 2003.

SUTHERLAND, Kevin S., WEHBY, Joseph H., COPELAND, Susan R. Effect of Varying Rates of Behavior-Specific Praise on the On-Task Behavior of Students with EBD. Journal of Emotional and Behavioral Disorders, [S.I.], v. 8, n. 1, p. 2-8, 2000.

SUTHERLAND, Kevin, et al. Examining the influence of teacher behavior and classroom context on the behavioral and academic outcomes for students with emotional or behavioral disorders. The Journal of Special Education, Austin, v. 41, n. 4, p. 223-233, fev. 2008.

SWEIGART, Chris A., et al. An Evaluation of the Evidence Base for Performance Feedback to Improve Teacher Praise Using CEC's Quality Indicators. Education and Treatment of Children, [S.I.], v. 39, n. 4, p. 419-444, mai. 2016.

TESTA, James. The Thomson Reuters Journal Selection Process. Transnational Corporations Review, [S.I.], v. 1, n. 4, p. 59-66, dez. 2015.

TORGESEN, Joseph K., et al. Intensive Remedial Instruction for Children with Severe Reading Disabilities: immediate and long-term outcomes from two instructional approaches. Journal of Learning Disabilities, [S.I.], v. 34, n. 1, p. 33-58, jan. 2001.

UNESCO - United Nations Educational, Scientific and Cultural Organization. The Dakar Framework for Action: Education for All. Paris: UNESCO; 2000. Disponível em: https://unesdoc.unesco.org/ark:/48223/pf0000121147. Acesso em: 7 mai. 2020.

VAUGHN, Sharon; GERSTEN, Russell; CHARD, David J. The Underlying Message in LD Intervention Research: Findings from Research Syntheses. Exceptional Children, [S.I.], v. 67 , n. 1, p. 99-114, out. 2000. 
VILELA-RIBEIRO, Eveline Borges; BENITE, Anna Maria Canavarro; LIMA-RIBEIRO, Matheus de Souza. Análise cienciométrica em Educação Especial: tendências e importância nos últimos 60 anos. Revista Educação Especial, Santa Maria, v. 24, n. 40, p. 285-304, mai. 2011.

VOSGERAU, Dilmeire Sant'Anna Ramos; ROMANOWSKI, Joana Paulin. Estudos de revisão: Implicações conceituais e metodológicas. Diálogo Educacional, Curitiba, v. 14, n. 41, p. 165-189, jan. / abr. 2016.

WAKEFIELD, Jerome C. DSM-5: An Overview of Changes and Controversies. Clinical Social Work Journal, [S.I.], v. 41, n. 2, p. 139-154, mai. 2013.

\section{Correspondência}

Mônica Luciana da Silva Pereira - Instituto Federal de Brasília, Campus Samambaia, Rodovia DF-460, Campus IFB, Lote 02 (Complexo Boca da Mata), Samambaia Sul (Samambaia), Brasília, Distrito Federal - Brasil.

CEP: $72304-300$

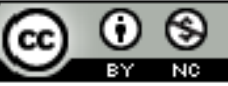

This work is licensed under a Creative Commons Attribution-NonCommercial 4.0 International (CC BY-NC 4.0) 